\title{
Research on Error Compensation Technology for CNC
}

\section{Machining}

\author{
Xianfeng Chen ${ }^{1, \mathrm{a}}$ and Weiming Zhang ${ }^{1, \mathrm{~b}}$ \\ ${ }^{1}$ School of Mechanical and Energy Engineering, Tongji University, 4800 Cao'an Road, Shanghai, China \\ ${ }^{\mathrm{a}}$ Email: xianfeng_chen@126.com, ${ }^{\mathrm{b}}$ Corresponding Email: iamt@tongji.edu.cn,
}

\begin{abstract}
Aiming at the thermal error problem in the procedure process of CNC machine, this study develops a new thermal error compensation technology. First, spindle and linear axis error are analyzed and measured. Then, a comprehensive error compensation model are proposed, which combined with spindle and linear axis. Finally, we use an example to illustrate the proposed method. Experimental results have shown that the proposed approach is able to reduce the influence of the thermal error on machining precision.
\end{abstract}

Keywords. Error Compensation, spindle and linear axis, multiple regression model.

\section{Introduction}

Recently, the CNC machine processing center plays a more and more important role in the manufacturing industry, it's important for companies to solve the problem about how to improve the machining efficiency and machining quality of the machine.

With the rapid development of CNC machining technology of China, the CNC machine accuracy has been greatly improved. With the unceasing enhancement of the CNC machine manufacturing technology and processing technology, there has got a solution for original machine tool error and machining error. However, it is important and difficult to eliminate the thermal error caused by temperature change and machine tool geometric error caused by the cutting load which affects the CNC machining accuracy [1].

In this study, we researched the measuring process and compensation mechanism of thermal error and geometric error. An error resource model and a new thermal error compensation technology are proposed.

\section{Relate work}

The research shows that thermal error is one of the main factors which influence the CNC machining accuracy. Temperature control method [2], thermal stability design [3], thermal error compensation [4] are the main three methods to eliminate the thermal error. However, the temperature control method is not easy to realize, because the temperature control mechanism is always lagging behind the temperature rise. The thermal stability design is difficult to analyze by the heat transfer process which is very complex and caused by the irregular structure of the machine tool. Thermal error compensation control technology is a kind of "soft" approach which do not need to change the machine 
parts, and can online real-time compensation, so it is has been widely accepted by the researchers. However, the Technology was blocked in the Advanced CNC control system, such as Siemens 840D and FANUC30i.

According to the structure characteristics of vertical CNC machining center, this study did a large amount of experiments under different operating conditions, proposed a thermal error prediction model to on-line predict the thermal error compensation and reduce the influence of the thermal error on machining precision.

\section{Error compensation technology}

\subsection{Error analysis}

\subsubsection{Spindle error analysis and measurement}

The spindle thermal error is caused by the thermal displacement between tool and the workbench, due to the effect of heat source of both inside and outside.

AS shown in the figure1, the spindle thermal displacement contains the axial thermal elongation $\mathrm{dz}(\mathrm{Z})$, the $\mathrm{X}$ axis thermal elongation $\mathrm{dx}(\mathrm{X})$ and the $\mathrm{Y}$ axis thermal elongation $\mathrm{dy}(\mathrm{Y})$.

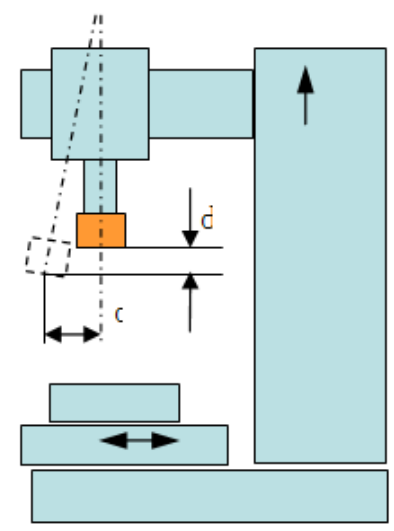

Fig.1. The spindle thermal displacement.

Five point method is adopted to measure the system thermal deformation parameter. Five point method which based on the theory of error separation and redundant information can minimize measurement results by reducing the reading error. And it widely used as a standard method for its high measurement accuracy and simple measurement.

AS shown in the figure2, five point method is adopted to improve the thermal error measurement. The environmental temperature measuring point (1), spindle temperature sensor (2), test mandrel (3), laser displacement sensor (4), bracket (5), the retaining bolt (6) are designed in different plane XY,XZ, YZ.

\subsubsection{Linear axis error analysis and measurement}

The linear axis includes $\mathrm{X}$ axis, $\mathrm{Y}$ axis, and $\mathrm{Z}$ axes axis. The main heat source of linear axis are the heating of the motor, the rotating heat of the ball screw bearing seat, friction heat of screw and nut. The thermal error of the linear axis measurement step are, firstly, using laser interferometer measure the segmentation accuracy of linear axis of machine tool, then, let the linear axes empty run back and quick heating and warming. After a period of time, do the measurement positioning precision again, such a loop, and change the position precision under the different heat condition. The cycle operation and measurement signal of the linear axis $\mathrm{X}$ is shown as Figure 3. 

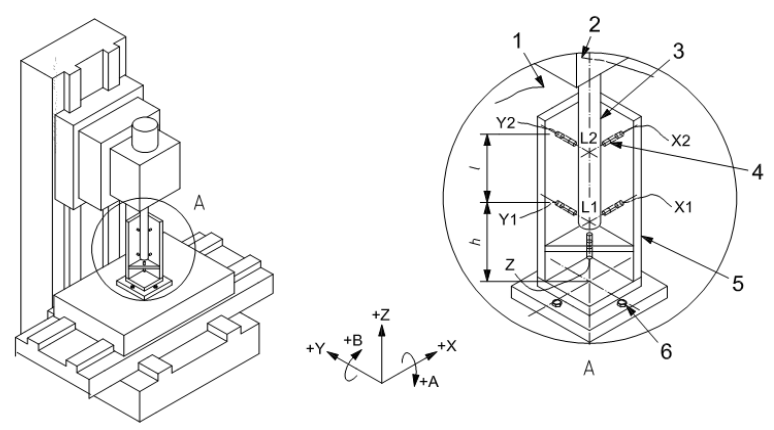

Fig. 2. Five point method.

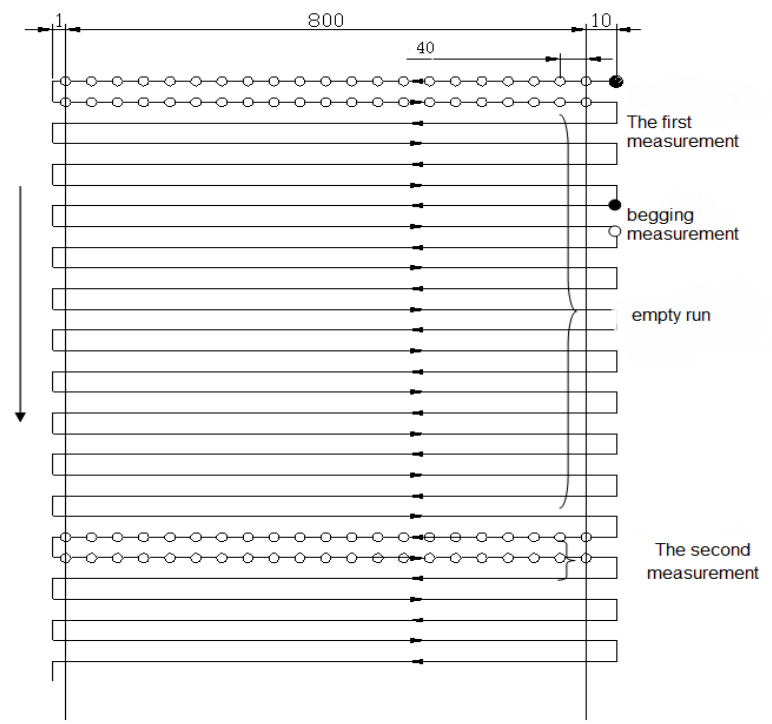

Fig. 3. The cycle operation and measurement signal of the linear axis $\mathrm{X}$.

\subsection{Model building}

\subsection{1 spindle thermal error modeling}

Traditionally, the linear systems including univariate and multivariate are used to build engineering model. However, with the unceasing development of artificial intelligence, the neural network, genetic algorithm and fuzzy modeling technology are widely used in nonlinear systems.

In this study, a multiple regression model, which based on the spindle's thermal deformation mechanism of machine tool and the characteristics of the $\mathrm{CNC}$ control system, are proposed to analyze the spindle thermal error.

According to the analysis of information entropy clustering, and multivariate regression modeling method, the spindle thermal deflection deformation in the $\mathrm{X}$ direction, can be represented as formula 1:

$$
\operatorname{Dx}(\mathrm{T})=\mathrm{a} 0+\mathrm{a} 1 * \mathrm{t} 1+\mathrm{a} 2 * \mathrm{t} 2+\mathrm{a} 3 * \mathrm{t} 3+\mathrm{a} 4 * \mathrm{t} 4
$$

Here, ti $(i=1,2,3,4)$ said the optimized heat sensitive temperature respectively, ai is the model coefficients. 
When the each parameter coefficient is calculated from the temperature and deformation data, the error model can be established. As the same with $\mathrm{X}$ direction, the multiple regression model of spindle thermal deflection deformation in the $\mathrm{Y}$ and $\mathrm{Z}$ direction can be calculated.

\subsubsection{The Linear axis thermal error modeling}

The figure 4 shows that the thermal error of linear axis $\mathrm{X}$ under $\mathrm{T}$ temperature, and it can be linear fitting. $\mathrm{K} 0$ is the error on the position $\mathrm{P} 0, \mathrm{Kx}$ is the error on the position $\mathrm{Px}$, and the error curve slope $\tan \beta$ (temperature compensation coefficient) can be calculated in formula 2 . Then the thermal error $(\mathrm{Kx})$ of linear axis $\mathrm{X}$ under $\mathrm{T}$ temperature can be represented as formula 3 .

$$
\begin{gathered}
\tan \beta(T)=\left(T-T_{0}\right) \cdot \frac{T K_{\max }}{T_{\max }-T_{0}} \\
\mathrm{Kx}=\mathrm{K} 0(\mathrm{r})+\tan \beta(\mathrm{T}) \cdot(\mathrm{Px}-\mathrm{P} 0)
\end{gathered}
$$

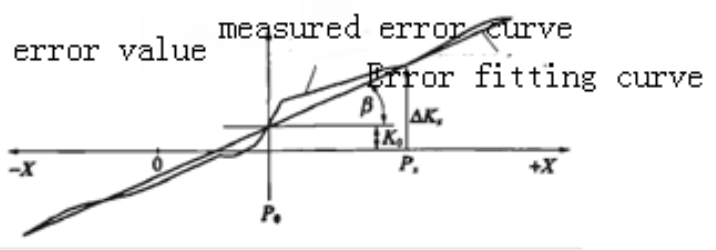

Fig. 4. The thermal error of linear axis $\mathrm{X}$ under $\mathrm{T}$ temperature.

\subsubsection{The comprehensive error compensation model}

The error compensation should consider the relative error of spindle and linear axis. So the comprehensive error compensation model can be described as follows (take the $\mathrm{X}$ axis as the example) .

$$
\mathrm{Dx}=-(\mathrm{Dx}(\mathrm{T})+\Delta \mathrm{Kx})=-(\mathrm{a} 0+\mathrm{a} 1 * \mathrm{t} 1+\mathrm{a} 2 * \mathrm{t} 2+\mathrm{a} 3 * \mathrm{t} 3+\mathrm{a} 4 * \mathrm{t} 4+\mathrm{K} 0(\mathrm{r})+\tan \beta(\mathrm{T}) \cdot(\mathrm{Px}-\mathrm{P} 0))
$$

\section{Case for error compensation technology}

The research on error compensation can reduce the impact of machine tool movement and instability. Fig. 5 shows the effect of the abrupt change of error compensation on speed. The original interpolation output instruction is displayed on figure 5 (a). When the machine is running at high acceleration, the error compensation is change from 0um to one 50um. It can be seen from the figure5 (b), the acceleration exceeds a predetermined allowable range if the output of the instruction signal occurs a jump.

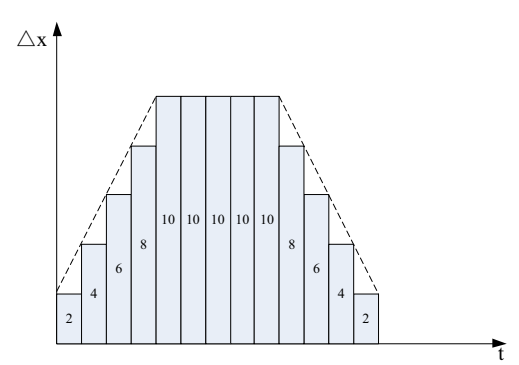

Fig. 5.(a)Instruction diagram after interpolation.

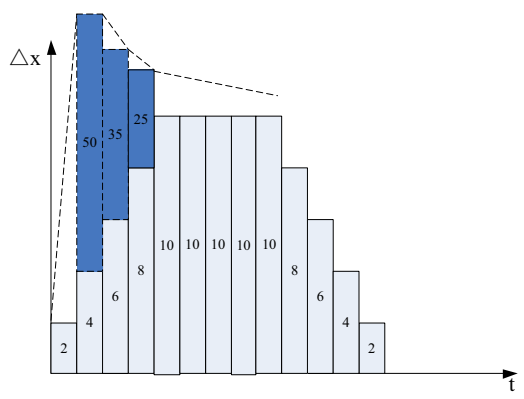

Fig. 5.(b)Instruction diagram after compensation. 


\section{Conclusion}

We present an error compensation technology for CNC machine in this research. The experiment results have shown that the proposed method can reduce the influence of the thermal error on machining precision. However, improving the machining efficiency and reduce the error should be keep improving.

\section{Acknowledgement}

This work is supported by the Key Projects in the National Science \& Technology Pillar Program during the Twelfth Five-year Plan Period (2012BAF01B02) "Key technologies development and application demonstration for high speed CNC machine tool of green manufacturing." The authors would like to thank all the members of the projects.

\section{References}

1. Miao, EM; Liu, Y; Liu, H; GAO, ZH; Li, W. Study on the effects of changes in temperature -sensitive points on thermal error compensation model for CNC machine tool. INT J MACH TOOL MANU 97:50-59(2015).

2. Guo, QJ ; Xu, RF ; Yang, TY; He, L; Cheng, X; Li, ZY; Yang, JG . Application of GRAM and AFSACA-BPN to thermal error optimization modeling of CNC machine tools. INT J ADV MANUF TECH 83(5-8): 995-1002(2016).

3. Liu, K ; Liu, Y; Sun, MJ ; Wu, YL; Zhu, TJ. Comprehensive thermal compensation of the servo axes of CNC machine tools. INT J ADV MANUF TECH 85(9-12): 2715-2728(2016).

4. Jie, G; John, S. A ; Sheri, K; CNC machine tool work offset error compensation method. Journal of Manufacturing Systems 37(2):576-585. 